\title{
The effects of $\boldsymbol{N}$-Acetylcysteine on frontostriatal resting-state functional connectivity, withdrawal symptoms and smoking abstinence: A double-blind, placebo-controlled fMRI pilot study*
}

\author{
B. Froeliger $^{1,2,{ }^{* \star}}$, P.A. McConnell ${ }^{1}$, N. Stankeviciute ${ }^{1}$, E.A. McClure ${ }^{3}$, P.W. Kalivas ${ }^{1}$, and \\ K.M. Gray ${ }^{3}$ \\ ${ }^{1}$ Department of Neuroscience, Medical University of South Carolina \\ ${ }^{2}$ Hollings Cancer Center, Medical University of South Carolina \\ ${ }^{3}$ Department of Psychiatry, Medical University of South Carolina
}

\section{Abstract}

BACKGROUND—Chronic exposure to drugs of abuse disrupts frontostriatal glutamate transmission, which in turn meditates drug seeking. In animal models, $N$-acetylcysteine normalizes dysregulated frontostriatal glutamatergic neurotransmission and prevents reinstated drug seeking; however, the effects of $N$-Acetylcysteine on human frontostriatal circuitry function and maintaining smoking abstinence is unknown. Thus, the current study tested the hypothesis that $\mathrm{N}$-Acetylcysteine would be associated with stronger frontostriatal resting-state functional connectivity (rsFC), attenuated nicotine withdrawal and would help smokers to maintain abstinence over the study period.

METHODS-The present study examined the effects of $\mathrm{N}$-Acetylcysteine on frontostriatal rsFC, nicotine-withdrawal symptoms and maintaining abstinence. Healthy adult, non-treatment seeking smokers ( $N=16$; mean (SD) age 36.5 \pm 11.9 ; cigs/day 15.8 \pm 6.1 ; yrs/smoking $15.7 \pm 8.9$ ) were randomized to a double-blind course of $2400 \mathrm{mg} N$-Acetylcysteine (1200 $\mathrm{mg}$ b.i.d.) or placebo over the course of $3 \frac{1}{2}$ days of monetary-incentivized smoking abstinence. On each abstinent day, measures of mood and craving were collected digitally and participants attended a lab visit in

\footnotetext{
*Supplementary material can be found by accessing the online version of this paper at http://dx.doi.org and by entering doi:...

${ }^{* *}$ Address for correspondence: Brett Froeliger, The Medical University of South Carolina, 96 Jonathan Lucas St., Neuroscience Research, MSC 606, Charleston, SC 29425; Telephone: (843) 792-6018; froelige@ musc.edu.

Conflicts of interest statement

No conflict declared

Contributors

Brett Froeliger was the Principle Investigator and designed the experimental paradigm. Patrick McConnell conducted data analysis and participated in manuscript preparation. Neringa Stankeviciute conducted participant recruitment, data collection and provided feedback on the manuscript. Erin McClure contributed to the development of study procedures. Peter Kalivas provided feedback on the experimental design and study concepts. Kevin Gray was the study Physician and Co-Investigator, and contributed to the development of the manuscript. All authors have approved the manuscript.

The authors report no conflicts of interest.

Publisher's Disclaimer: This is a PDF file of an unedited manuscript that has been accepted for publication. As a service to our customers we are providing this early version of the manuscript. The manuscript will undergo copyediting, typesetting, and review of the resulting proof before it is published in its final citable form. Please note that during the production process errors may be discovered which could affect the content, and all legal disclaimers that apply to the journal pertain.
} 
order to assess smoking (i.e., expired-air carbon monoxide [CO]). On day 4, participants underwent fMRI scanning.

RESULTS-As compared to placebo ( $n=8)$, smokers in the $N$-Acetylcysteine group $(n=8)$ maintained abstinence, reported less craving and higher positive affect (all $p$ 's <.01), and concomitantly exhibited stronger rsFC between ventral striatal nodes, medial prefrontal cortex and precuneus—-key default mode network nodes, and the cerebellum [ $p<.025 ; \mathrm{FWE}])$.

CONCLUSIONS-Taken together, these findings suggest that $N$-Acetylcysteine may positively affect potentially dysregulated corticostriatal connectivity, help to restructure reward processing, and help to maintain abstinence immediately following a quit attempt.

\section{Keywords}

accumbens; cingulate; cigarette; nicotine; rsfc; glutamate

\section{INTRODUCTION}

Nicotine addiction is the leading cause of preventable premature death in the USA (CDC, 2002), costing nearly $\$ 200$ billion each year (AHA et al., 2010). Despite the relative effectiveness of current first-line medications for promoting smoking abstinence (Cahill et al., 2013; Gonzales et al., 2006; Jorenby et al., 2006; Oncken et al., 2006), most quit attempts result in relapse (Cahill et al., 2013). Therefore, further research examining new medications for treating the neuropathophysiology of nicotine addiction is needed in order to help initiate and maintain smoking abstinence and prevent relapse.

Chronic drug abuse produces neuroplasticity in frontostriatal (i.e., medial prefrontal cortex: mPFC, nucleus accumbens: NAcc) glutamatergic circuitry, which subserves compulsive drug seeking and the loss of adaptive behavioral responding to changing environmental contingencies (Kalivas, 2009). In animal models, chronic nicotine exposure-the primary psychoactive component of tobacco (Stolerman and Jarvis, 1995)—is shown to impair functioning of the glial glutamate transporter (GLT-1) in the NAcc (Gipson et al., 2013). Impaired GLT-1 function decreases the rate of glutamate elimination from the extracellular space, thereby augmenting the spillover of synaptically-released glutamate during reinstated drug seeking (Baker et al., 2003; Berglind et al., 2009; Pierce et al., 1996). Increased release of synaptic glutamate, derived from mPFC (e.g., anterior cingulate cortex; ACC) synapses in the NAcc core, stimulates extrasynaptic glutamate receptors which cause the rapid, transient synaptic potentiation required for reinstatement of nicotine seeking (Gipson et al., 2013). Consistent with findings from animal models, human positron emission tomography (PET) research using a glutamate receptor ligand reveals that, as compared to both nonsmokers and former cigarette smokers, current smokers have elevated glutamate receptor occupancy in the mPFC (Akkus et al., 2013). This observation potentially resulted from reduced glutamate receptor density or changes in affinity of the glutamate binding site, either of which may be a result of smoking or a predisposing factor in nicotine addiction (Akkus et al., 2013). Further, cue-induced craving is associated with greater functional magnetic resonance imaging (fMRI) blood-oxygenation-level-dependent (BOLD) response in the ventral striatum/NAcc (Bell et al., 2014; Jasinska et al., 2014) and mPFC (McClernon et al., 2009; 
Wilson and Sayette, 2014); critically, the magnitude of smoking cue-reactivity in the mPFC predicts relapse (Janes et al., 2010).

Resting-state functional connectivity (rsFC) fMRI has emerged as an effective method for examining systems-level functional connectivity [Biswal et al., 1995; i.e., fluctuating BOLD activation in distributed neural networks (Shmuel and Leopold, 2008)]. Recently, combined human rsFC and magnetic resonance spectroscopy (MRS) evidence has been reported linking $\mathrm{mPFC}$ glutamate concentrations to $\mathrm{rsFC}$ in frontostriatal circuitry via positive correlation (Duncan et al., 2013). Interestingly, elevated mPFC glutamate concentrations have also been associated with mental imagery (Huang et al., 2015); when considering the role of imagery in drug craving (Taylor et al., 2000), this finding offers a plausible mechanism through which elevated mPFC glutamate concentrations may contribute to frontostriatal desynchronization. Indeed, other rsFC studies have revealed that frontostriatal rsFC is weaker among drug-dependent populations, including nicotine dependence (Hong et al., 2009), opiate addiction (Ma et al., 2010) and polysubstance abuse (Motzkin et al., 2014). Thus, a convergence of evidence from animal models and human research stresses the need for a principled investigation of novel glutamatergic pharmacotherapies for treating frontostriatal circuitry in an effort to prevent smoking relapse (Reissner and Kalivas, 2010).

$\mathrm{N}$-acetylcysteine, a cysteine prodrug that regulates intra- and extra-cellular glutamate, holds promise as a medication to normalize frontostriatal function and prevent relapse. $\mathrm{N}$ Acetylcysteine exerts antioxidant properties via activation of the cystine-glutamate exchanger (Dringen et al., 2001; Lewerenz et al., 2013) and, in animal models, is shown to restore GLT-1 function that has been down-regulated by chronic use of addictive drugs (Baker et al., 2003). Preclinical models show that $N$-Acetylcysteine blocks reinstated drugseeking (Reichel et al., 2011) and restores glutamatergic synapses in the NAcc (Kupchik et al., 2012; Moussawi et al., 2009). Clinically, $N$-Acetylcysteine is shown to be safe and welltolerated (LaRowe et al., 2006; Mardikian et al., 2007; McClure et al., 2014b) and some evidence suggests that $N$-Acetylcysteine may treat frontostriatal glutamate-mediated behavior. In a MRS study of cocaine-dependent individuals (Schmaal et al., 2012), acute administration of $N$-Acetylcysteine normalized elevated glutamate levels in the mPFC (i.e., dACC). Further, $N$-Acetylcysteine has been shown to significantly attenuate withdrawalinduced craving for cocaine (LaRowe et al., 2006), and in an open label trial, reduce marijuana use and craving in adolescent marijuana users (Gray et al., 2010). In spite of the nascent database on $\mathrm{N}$-Acetylcysteine's potential role in treating substance-use disorders (SUDs; McClure et al., 2014b) and compulsive behaviors (Berk et al., 2013) more broadly, only a few studies have reported — with mixed findings - the effects of $\mathrm{N}$-Acetylcysteine on smoking behavior (Knackstedt et al., 2009; Prado et al., 2015; Schmaal et al., 2011). Nevertheless, the majority of research conducted in animal models has been performed in the context of reinstatement paradigms, suggesting that $\mathrm{N}$-Acetylcysteine may be most effective under conditions of abstinence. Indeed, the administration of $\mathrm{N}$-Acetylcysteine to abstinent smokers significantly attenuates perceived reward from smoking following an adlib smoking period (Schmaal et al., 2011). Taken together, the literature suggests that $\mathrm{N}$ Acetylcysteine may be most effective in treating frontostriatal circuitry function under conditions of abstinence, and thus may help to prevent relapse; however, the effects of $N$ - 
Acetylcysteine on systems-level neural function in humans and long-term smoking behavior remains unknown. Hence, further research is needed to examine the clinical efficacy of $\mathrm{N}$ Acetylcysteine for smoking cessation. The present study aimed to test the hypothesis that administering $\mathrm{N}$-Acetylcysteine to nicotine-dependent smokers, while abstinent from cigarettes, would be associated with stronger rsFC in the frontostriatal pathway; modulate frontostriatal mediated behaviors, including craving and positive mood; and help to prevent lapse/relapse over the course of a $3 \frac{1}{2}$ day study period—a timeframe representative of greatest relapse vulnerability (Westman et al., 1997).

\section{MATERIALS AND METHODS}

\subsection{Participant Characteristics, Recruitment \& Screening Procedures}

Seventeen adult nicotine-dependent smokers were recruited from the community, met all inclusion/exclusion criteria, and completed all aspects of the study. Smokers were included if they were generally healthy, smoked $\geq 10$ cigarettes/day of a brand delivering $>.05 \mathrm{mg}$ of nicotine according to the standard Federal Trade Commission method, for at least 2 years, were not using any nicotine products other than cigarettes - including e-cigarettes - and were not immediately interested in quitting smoking. Smokers were required to have an afternoon expired-air carbon monoxide (CO) level $\geq 10 \mathrm{ppm}$ during the screening visit and report at least moderate nicotine dependence (FTND $\geq 3$ : see below). Exclusion criteria included: use of carbamazepine and/or nitroglycerin within the past 14 days; current/history of a serious health or psychiatric disorder; use of medications altering CNS functioning; a positive urine drug screen; any condition making MRI research unsafe; and among females, a positive urine pregnancy test. All participants read and signed a Medical University of South Carolina (MUSC) Institutional Review Board (IRB) approved informed consent form. All procedures were approved by the MUSC IRB. Participants completed a screening visit where they provided biological samples, underwent a medical evaluation, completed surveys and trained in a mock scanner. One participant was excluded from the analyses for not following task instructions on the questionnaires and during the fMRI scanning protocol, thus resulting in a final $N=16$ (Table 1).

\subsection{Pharmacological Procedure}

In a double-blind, placebo-controlled design, smokers were randomly assigned to receive either $2400 \mathrm{mg} N$-Acetylcysteine (1200 mg b.i.d.), or placebo, daily over the course of $3 \frac{1}{2}$ days of monetary-incentivized smoking abstinence (\$50/day), and participated in an fMRI session on day 4 . On study days 1-3, participants attended brief lab visits in order to provide: 1) a biochemical measure of smoking: expired $\mathrm{CO}$; and 2) to assess for any adverse events. Following the fMRI visit, the participant and the researcher conducting the experiment were each asked to independently record which medication they perceived was administered during the study.

\subsection{Behavioral Assessment and Analyses}

2.3.1 Baseline measures-Smokers completed the Fagerström Test for Nicotine Dependence (FTND) (Heatherton et al., 1991). Depressive symptoms were assessed with the Center for Epidemiological Studies-Depression (CES-D) scale (Radloff, 1977). Cognitive 
status was assessed with the Cognitive Failures Questionnaire (CFQ; Broadbent et al., 1982).

2.3.2 Assessment of craving and affect-Smokers filled out digital surveys, via text messaging, querying craving and mood states randomly throughout each day. Statedependent withdrawal symptoms were measured using the modified version of the Shiffman-Jarvik Withdrawal Questionnaire (SJWQ; Shiffman and Jarvik, 1976). Statedependent mood was measured using the 20-item positive and negative affect schedule (PANAS; Watson et al., 1988). On the fMRI visit, state craving was also assessed using an 8-point Likert Scale querying the subject "How much do you crave a cigarette right now?"; 1 indicating "Not at all" and 8 indicating "Extremely".

2.3.3 Biochemically confirmed smoking-At the beginning of each of the 5 visits (screening, abstinence days $1-3$, and day 4-fMRI visit), smoking was biochemically assessed via expired breath CO concentration (PPM; (Vitalograph BreathCO Monitor, Lenexa, KS).

\subsection{Behavioral Analyses}

Behavioral analyses were performed with $a=.05$ using Greenhouse-Geisser corrected degrees of freedom. Between-subjects repeated-measures analyses of covariance (RMANCOVAs) were performed in SPSS independently for positive (PA) and negative (NA) affect, the SJWQ symptom subscale, and expired-air CO concentration. RM-ANOVA $(2 \times 4)$ for PA/NA and RM-ANCOVA for SJWQ, assessed mean variance across 4 time-points (abstinence days 1, 2, 3 and 4 (fMRI visit)) while controlling for years smoking in the SJWQ analysis. Baseline SJWQ and PANAS data were missing for one Placebo subject so were excluded from the analyses. RM-ANCOVA $(2 \times 3)$ for CO, reported in Table 3.a., excluded day 3 from analysis due to missing $\mathrm{CO}$ data from 4 subjects (2/group) and controlled for both baseline $\mathrm{CO}$ and for years smoking. Simple main effects of group at each time point were assessed post hoc using $t$-tests. Where significant main effects of group or group $\mathrm{x}$ time interactions were observed, variables were further explored via correlational analysis with regard to their relationships with the different resting-state pathways. To control for family-wise error across dependent measures in these correlational analyses, we adjusted the alpha levels for the number of total comparisons for each pathway: 2 subjective (positive affect and craving; $\alpha=0.025)$ and 1 objective $(\mathrm{CO} ; \alpha=0.05)$. Lastly, to assess state craving on the experimental visit, ANCOVA was used to assess group differences, controlling for years smoking.

\subsection{Neuroimaging Data Acquisition, Processing and Analyses}

2.5.1 Data Acquisition-Data were collected on a Siemens Magnetom TrioTim 3T MR scanner (Siemens, Erlangen, Germany) with a 32-channel head coil. A 3D, T1-weighted, multi-planar rapid gradient-echo (MPRAGE) sequence was used to acquire high-resolution $\left(1 \mathrm{~mm}^{3}\right.$ voxel) structural images. Next, a 6-min, eyes-closed rsFC scan was acquired using an echo-planar gradient-echo pulse sequence $\left(\mathrm{TR}=2000 \mathrm{~ms}, \mathrm{TE}=30 \mathrm{~ms}\right.$, flip angle $=90^{\circ} ; 36$ transverse slices, $3.0 \mathrm{~mm}$ thickness, $0.58 \mathrm{~ms}$ gap; voxel size was $3.3 \mathrm{~mm} \times 3.3 \mathrm{~mm} \times 3.0 \mathrm{~mm}$ ). 
Data processing: Structural images were pre-processed using the VBM8 toolbox (dbm.neuro.uni-jena.de/vbm8) for SPM12 (www.fil.ion.ucl.ac.uk/spm). Data were preprocessed according to default settings: bias correction; tissue classification/segmentation (Rajapakse et al., 1997); partial volume estimation (PVE; Tohka et al., 2004); denoising/ filtering (Manjón et al., 2010; Rajapakse et al., 1997); warping to the DARTEL IXI-550 template in Montreal Neurologic Institute (MNI) space; and resampling to a $1.5 \mathrm{~mm}^{3}$ voxelsize using affine and nonlinear transforms (Ashburner, 2007). Forward-deformation fields were calculated from each subject's skull-stripped and rigid-body registered T1 (PVE) image in order to warp functional data into MNI space. Preprocessing of functional data included: slice time correction and realignment (Friston et al., 1994); motion outlier detection (framewise displacement $>1 \mathrm{~mm}$; www.nitrc.org/projects/artifact_detect) and correction (via interpolation; cibsr.stanford.edu/tools/human-brain-project/artrepairsoftware.html); coregistration of functional images to PVE image; warping to MNI space using forward deformations and resampling to $1.5 \mathrm{~mm}^{3}$ voxel size; and smoothing with a $10 \mathrm{~mm}^{3}$ FWHM Gaussian filter. Motion was corrected for ten subjects $(n=3, N$ -

Acetylcysteine; $n=7$, Placebo). Exclusion threshold for rapid motion was $20 \%$ of run length but no subjects exceeded this threshold. Mean volumes corrected did not differ significantly between groups $(t(14)=1.4, p=.194)$.

2.5.2 Denoising of functional images-Modeled data were uploaded into the conn14 toolbox (www.nitrc.org/projects/conn) for denoising and connectivity analyses. Unsmoothed segmented tissue images, along with region of interest (ROI) masks ( $5 \mathrm{~mm}$ radius spheres around coordinates of interest, comprising $523.6 \mathrm{~mm}^{3}$ ) were uploaded into the toolbox. Mean time-courses from the unsmoothed BOLD signal from each ROI were characterized with no additional principal components. Confounds (mean white matter (WM) and cerebrospinal fluid (CSF) signal, and motion) were regressed out of the mean signal for each ROI. Analysis space was set to match the functional images (i.e., $1.5 \mathrm{~mm}^{3}$ ) with an explicit mask generated by skull-stripping the DARTEL IXI-550 template image. A band-pass filter of .008 to $.09 \mathrm{~Hz}$ with despiking performed after confound regression (no detrending) was used.

2.5.3 fMRI data analysis-All fMRI data analyses were performed with conn14 toolbox for SPM12. Hypothesis testing was conducted using seed-to-voxel bivariate correlations with sources comprising L/R.NAcc ( $\pm 12,8,-8)$ (Zink et al., 2003). At the group level, effects of medication were examined with $t$-tests, correcting for multiple comparisons using $p<.025 \mathrm{FWE}$ at the cluster level $(p<.001$ cluster-forming threshold). Among significant clusters, weighted means from each ROI were extracted and used for descriptive statistics (mean, SD, cohen's $d$ ).

\section{RESULTS}

\subsection{Blind Success and Adverse Events}

The double-blind procedure used in the study was successful. Neither participants $\left[X^{2}(2, N\right.$ $=16)=1.72, p=.19]$ nor the researcher $\left[X^{2}(1, N=16)=2.28 .1, p=.131\right]$ were able to identify the condition. A total of 17 adverse events (AEs) (placebo: $n=12 ; N$ - 
Acetylcysteine: $n=5$ ) were reported for seven participants (44\%). All AEs were mild and consistent with symptoms that accompany smoking withdrawal (Table 2).

\subsection{Behavioral Measures}

3.2.1 Carbon Monoxide-A significant group $\times$ time interaction $(F(1.83,21.97)=3.74$, $p=.043$ ) was identified; whereas compared to placebo group, the $N$-Acetylcysteine group exhibited significantly lower $\mathrm{CO}$ values beginning on abstinence day 2 and continuing to the fMRI visit (Table 3.a).

3.2.2 Daily self-report measures-A significant group $\times$ time interaction $(F(2.10,29.35)=3.66, p=.036)$ was identified for positive affect. As compared to the placebo group, the $N$-Acetylcysteine group reported a non-significant trend for higher positive affect beginning on Abst. Day 2 that was significant on Abst. Days 3 and 4 (Table 3.b). The group $\times$ time interaction and main effects of group and time for withdrawal symptoms (SJWQ) (see Table S1 ${ }^{1}$ ) and self-reported negative affect (see Table S2 ${ }^{2}$ ) failed to reach significance (all $p$ 's $>.3$ ).

State craving ratings: The groups exhibited a significant difference in craving rating on the experimental visit $(F(1,13)=9.54, p=.009)$; the $N$-Acetylcysteine group reported significantly less craving $(M=4.3 \pm 1.2)$ than the placebo group $(M=6.4 \pm 1.2)$ (Table 3.c).

\subsection{Effects of $\mathrm{N}$-Acetylcysteine on Bilateral Nucleus Accumbens rsFC}

Compared to placebo, smokers who received $N$-Acetylcysteine exhibited stronger rsFC in four striatal pathways: between R.NAcc and left medial prefrontal cortex (mPFC) and bilateral precuneus, and between L.NAcc and bilateral cerebellum and ventromedial prefrontal cortex (vmPFC) (see Table 4; Figure 1). Years smoking was not correlated with connectivity in any of the four pathways, so was not controlled for via regression analyses.

\subsection{Correlation Analysis of Relations between rsFC, Smoking Behavior and Self-Reported Craving and Mood}

\subsubsection{NAcc-Medial Prefrontal Pathways}

3.4.1.1 R.NAcc-mPFC Pathway: R.NAcc-mPFC rsFC was negatively correlated with $\mathrm{CO}$ $(r=-.50, p=.049)$ and approached significant negative correlation with craving $(r=-.48$, $p=.060$ ) on the fMRI visit. Additionally, rsFC in this circuit positively correlated with positive affect $(r=.69, p=.003)$ on the fMRI visit. No association between rsFC and negative affect was observed (Fig. 2).

3.4.1.2 L.NAcc-vmPFC Pathway: L.NAcc-vmPFC rsFC was negatively correlated with $\mathrm{CO}(r=-.69, p=.003)$ and craving $(r=-.71, p=.002)$ on the fMRI visit. Additionally, rsFC in this circuit positively correlated with PA $(r=.55, p=.028)$ on the fMRI visit. No association between $\mathrm{rsFC}$ and negative affect was observed (Fig. 2).

\footnotetext{
${ }_{1}^{1}$ Supplementary material can be found by accessing the online version of this paper at http://dx.doi.org and by entering doi:...

${ }^{2}$ Supplementary material can be found by accessing the online version of this paper at http://dx.doi.org and by entering doi:...
} 
3.4.1.3 R.NAcc-Precuneus Pathway: R.NAcc-Precuneus rsFC was negatively correlated with $\mathrm{CO}(r=-.52, p=.037)$ and craving on the fMRI visit $(r=-.50, p=.050)$.

Additionally, rsFC in this circuit approached significant positive correlation with positive affect on the fMRI visit $(r=.48, p=.061)$. No association between rsFC and negative affect was observed (Fig. 2).

3.4.1.4 L.NAcc-Cerebellum Pathway: L.NAcc-Cerebellum rsFC was negatively correlated with $\mathrm{CO}(r=-.63, p=.009)$ and craving $(r=-.62, p=.011)$ on the fMRI visit. Additionally, $\mathrm{rsFC}$ in this circuit positively correlated with positive affect $(r=.68, p=.004)$ on the fMRI visit. No association between rsFC and negative affect was observed (Fig. 2).

\subsection{Correlations between craving, mood and $\mathrm{CO}$ on the fMRI visit}

Across all smokers, craving and positive affect were negatively correlated $(r=-.586, p=$. $02)$; craving and negative affect were not ( $p$ 's $>.05)$. CO was negatively correlated with positive affect $(r=-.63, p=.009)$ and positively correlated with craving $(r=.58, p=.018)$.

\section{DISCUSSION}

The current study sought to: A) examine the effectiveness of $\mathrm{N}$-Acetylcysteine for treating dysregulated frontostriatal circuitry among nicotine-deprived smokers and B) preliminarily evaluate the potential value of using $N$-Acetylcysteine as a relapse-prevention aid. Results from this study revealed that, as compared to placebo, smokers assigned to a $31 / 2$ day course of $\mathrm{N}$-Acetylcysteine exhibited stronger rsFC between NAcc and mPFC/vmPFC (frontostriatal), between NAcc and key nodes of the default mode network (mPFC/ Precuneus) and between NAcc and cerebellum. Further, smokers who received $N$ Acetylcysteine reported higher PA and less craving on the fMRI visit and were able to successfully maintain smoking abstinence over the course of the study. While this study is limited due to the cross-sectional nature of the experimental design, these findings suggest that $N$-Acetylcysteine may help to normalize dysregulated frontostriatal circuitry function and restructure reward processing, and may provide a therapeutic benefit for preventing relapse during smoking cessation.

Addiction-related deficits in top-down, prefrontally-mediated cognitive control over affective and motivational responding are well documented (Goldstein and Volkow, 2002). For example, as compared to nonsmokers, smokers exhibit dysregulated prefrontal response during cognitive (Froeliger et al., 2013), affective (Augustus Diggs et al., 2013; Froeliger et al., 2013) and drug-related cue (Augustus Diggs et al., 2013) processing, and withdrawal engenders further disruption in prefrontal function across a broad array of tasks (Azizian et al., 2010; Froeliger et al., 2012a, 2012b, 2012c; Kozink et al., 2010). In addition to diminished prefrontal control, patients with substance use disorders exhibit potentiated BOLD response in the NAcc (which codes reward related signal; Knutson and Gibbs, 2007) to drug cues (Jasinska et al., 2014; Kilts et al., 2004; Kober et al., 2010). Conversely, the flexible deployment of prefrontal cortex is important in modulating ventral-striatal mediated cigarette craving (Kober et al., 2010). Thus, dysregulated cognitive control over motivational responding, contributing to the downward spiral of drug addiction (Garland et 
al., 2014), is posited to result from disrupted frontostriatal intra- and extra-cellular glutamate homeostasis (Kalivas, 2009), which may underpin a functional dysconnectivity.

\subsection{Effects of $\mathrm{N}$-Acetylcysteine on frontostriatal rsFC}

Indeed, drug addiction is evidenced by weakened frontostriatal rsFC (Hong et al., 2009; Ma et al., 2010; Motzkin et al., 2014). Of particular relevance to the current study, Hong et al. (2009) reported that nicotine-addiction severity was associated with weaker rsFC between mPFC (i.e., dACC) and ventral striatum during smoking abstinence and that acute nicotine administration failed to improve the strength of connectivity in this circuit. The current findings that $N$-Acetylcysteine administration was associated with stronger $\mathrm{rsFC}$ in frontostriatal circuitry — a reversal of the effects reported in Hong et al. (2009)—and attenuated smoking behavior to a biochemically confirmed level indicating abstinence, may suggest a reduction in dependence severity. These findings are consistent with research in animal models demonstrating that $N$-Acetylcysteine normalizes frontostriatal glutamate and prevents reinstated drug seeking. When taken together, the extant literature and current study findings suggest that restoring glutamatergic tone in the frontostriatal pathway may help to prevent smoking relapse and may also be one neurobiological mechanism through which the severity of addiction might be reduced.

Blunted positive affective response to natural environmental rewards is a salient feature of substance use disorders (Koob and Le Moal, 2001), especially when patients with substance use disorders are under conditions of withdrawal (Volkow et al., 1997). Addiction-related neuroplasticity in frontostriatal circuits have been implicated as critical pathways involved in restructuring reward processing, as evidenced by heightened reactivity to conditioned drug cues and attenuated responses to intrinsically positive stimuli (Koob and Le Moal, 2008). While the mPFC is pivotal in directing attention to salient reward-related stimuli (Knutson et al., 2000; Rogers et al., 2004; Rushworth et al., 2007), among patients with substance use disorders, the mPFC codes for cigarette craving (Wang et al., 2007) and is shown to become sensitized to detecting conditioned drug cues (Brody et al., 2002; McClernon et al., 2005). In addition, the NAcc plays a role in detecting changes in the magnitude of perceived reward (Knutson et al., 2001) and risk (Matthews et al., 2004); yet among patients with substance use disorders, accumbens' responsivity to drug cues varies as a function of craving intensity (Goldman et al., 2013; Kufahl et al., 2005; Li et al., 2012; Risinger et al., 2005) and the drug's perceived rewarding effects (Kufahl et al., 2005; Risinger et al., 2005). This restructuring of reward learning entrenches the drug user in a vicious cycle of drug taking that serves to maintain the ongoing use of drugs. Indeed, relapse vulnerability has been attributed to increased incentive salience of drug cues and decreased salience of intrinsically pleasant stimuli (Berridge et al., 2009; Koob and Le Moal, 2001). In the present study, the strength of rsFC in each striatal pathway was negatively correlated with craving, yet positively associated with positive affect. Consistent with the literature (Cook et al., 2004), positive affect and craving were inversely correlated on the fMRI visit while subjects were abstinent from smoking. Given that $N$-Acetylcysteine smokers did not differ from Placebo at baseline with regard to positive affect or craving, these patterns of findings support the hypothesis that $\mathrm{N}$-Acetylcysteine facilitates the restoration of control over motivational responding. The theoretical therapeutic mechanism of $N$-Acetylcysteine 
(i.e., normalizing frontostriatal glutamatergic neurotransmission) would thus explain the decreased craving and concomitantly increased positive affect observed in $\mathrm{N}$ -

Acetylcysteine-treated smokers during the withdrawal state. However, further research is needed to determine whether $N$-Acetylcysteine-normalized frontostriatal rsFC, and associated positive affect, might translate into normalized striatal BOLD response to natural rewards, and also to what extent this process of reward restructuring may be mediated by the effects of $N$-Acetylcysteine on mPFC glutamate concentrations.

\subsection{Effects of N-Acetylcysteine on Default Mode rsFC}

Precuneus and mPFC BOLD signals, key resting-state default-mode network (DMN) nodes, were also found to correlate more strongly with NAcc as a function of $\mathrm{N}$-Acetylcysteine administration, with stronger connectivity predicting reduced self-reported cigarette craving and greater positive affect. These DMN nodes have already been implicated in the pathophysiology of nicotine addiction, both in terms of structural and resting-state functional connectivity (Huang et al., 2014). Specifically, Huang and colleagues demonstrated that connectivity between precuneus and $\mathrm{mPFC}$ was increased proportionally with nicotine dependence and withdrawal-induced craving. Given the seed-voxel analytic strategy employed in the present study, we are unable to speak to the relationship between precuneus and $\mathrm{mPFC}$ with regard to $N$-Acetylcysteine administration; however, the present findings suggest that addiction-associated alterations in DMN connectivity may in part be mediated through each node's pattern of connectivity with the ventral striatum.

\subsection{Effects of N-Acetylcysteine on NAcc-Cerebellum rsFC}

Here, we report increased rsFC between NAcc and superior, bilateral cerebellum that was associated with the administration of $N$-acetylcysteine, reduced craving and increased positive affect. Task-based fMRI and volumetric VBM analyses have implicated regions of the cerebellum, and its connectivity with the striatum, in various forms of learning such as implicit motor learning (Tzvi et al., 2014) and reversal learning (Moreno-López et al., 2015). The cerebellum plays a role in reactive 'on-line' error correction in movement (Doya, 2000) and motor learning (Bastian, 2006). Smoking cessation can be viewed as a complex learning process - or rather an unlearning process - that involves not only alterations in reward processing and inhibitory control functioning, but also with regard to cravingassociated motor programs related to the prediction of smoking reward: such as reaching to one's pocket for a cigarette, or raising one's hand to their lips, etc. Further research is needed to elucidate the role that ventral striatal-cerebellar connectivity may play in motivational processes and drug self-administration.

\subsection{Summary, Limitations and Future Directions}

In sum, the current study findings suggest that $N$-Acetylcysteine may help to treat the neuropathophysiology of nicotine addiction and may prevent relapse, theoretically via alterations in functional communication between top-down control centers and striatal motivational centers. Limitations of the study include a small $N$; a relatively homogenous group of smokers; and a restrictive-yet focused, statistically rigorous, and hypothesis driven—rsFC analytic approach. Critically, although we had a priori hypotheses regarding 
rsFC between nucleus accumbens and $\mathrm{mPFC}$, we performed whole-brain analyses correcting for multiple-comparisons in a very conservative manner while also providing novel neurobehavioral findings correlating craving and positive affect with $N$-Acetylcysteineassociated changes in frontostriatal, striatal-DMN, and striatal-cerebellar rsFC. These findings alone have exciting clinical implications for $\mathrm{N}$-Acetylcysteine-assisted treatment for addictions, given that craving and dysregulated mood are primary precipitants to relapse (Shiffman et al., 1996). In addition, although prior research demonstrates that nicotine addiction severity is associated with weaker rsFC between ACC and ventral striatum, independent of whether nicotine is "on board", the current study design did not allow for dissociating the effects of NAC vs nicotine and/or tobacco on rsFC. Future large-scale studies that assess smoking behavior over an extended time-frame, and potentially in a controlled clinical environment are needed in order to inform clinical significance. Current study findings warrant consideration of using $\mathrm{N}$-Acetylcysteine as a means to help a smoker maintain abstinence in conjunction with medications that promote abstinence (McClure et al., 2014a), and/or behavioral interventions that train cognitive restructuring of reward processes (Garland et al., 2014). Finally, protocols that include MRS, to directly assess glutamate concentrations, along with rsFC and task-based BOLD fMRI signal may help to further elucidate the neurobiological and neurocognitive effects of $N$-Acetylcysteine on treating the neuropathophysiology of substance abuse disorders.

\title{
Supplementary Material
}

Refer to Web version on PubMed Central for supplementary material.

\section{Acknowledgments}

\author{
Role of funding \\ This study was supported by NIH/NIDA (R01DA0033459 [BF]; P50DA015369 [PWK]) and pilot funds provided \\ by P30CA138313 [Hollings Cancer Center] to BF. \\ The authors would like to thank the MUSC Center for Biomedical Imaging (CBI), Taylor Salo at the University of \\ California-Davis for his assistance with computer programming and the Reviewers of this manuscript for providing \\ thoughtful critiques and insightful comments.
}

\section{References}

Lloyd-Jones D, Adams RJ, Brown TM, Carnethon M, Dai S, De Simone G, Ferguson TB, Ford E, Furie K, Gillespie C, Go A, Greenlund K, Haase N, Hailpern S, Ho PM, Howard V, Kissela B, Kittner S, Lackland D, Marelli A, McDermott MM, Meigs J, Mozaffarian D, Mussolino M, Nichol G, Roger VL, Rosamond W, Sacco R, Sorlie P, Stafford R, Thom T, Wasserthiel-Smoller S, Wong ND, Wylie-Rosett J. AHA; AHA Committee Stroke Statistics Subcommittee. Heart Disease and Stroke Statistics--2010 Update: A Report From the American Heart Association. Circulation. 2010; 121:e46-215. [PubMed: 20019324]

Akkus F, Ametamey SM, Treyer V, Burger C, Johayem A, Umbricht D, Gomez Mancilla B, Sovago J, Buck A, Hasler G. Marked global reduction in mGluR5 receptor binding in smokers and exsmokers determined by [11C]ABP688 positron emission tomography. Proc Natl Acad Sci U S A. 2013; 110:737-742. [PubMed: 23248277]

Ashburner J. A fast diffeomorphic image registration algorithm. Neuroimage. 2007; 38:95-113. [PubMed: 17761438] 
Augustus Diggs H, Froeliger B, Carlson JM, Gilbert DG. Smoker-nonsmoker differences in neural response to smoking-related and affective cues: an fMRI investigation. Psychiatry Res. 2013; 211:85-87. [PubMed: 23146252]

Azizian A, Nestor LJ, Payer D, Monterosso JR, Brody AL, London ED. Smoking reduces conflictrelated anterior cingulate activity in abstinent cigarette smokers performing a Stroop task. Neuropsychopharmacology. 2010; 35:775-782. [PubMed: 19907418]

Baker DA, McFarland K, Lake RW, Shen H, Toda S, Kalivas PW. N-acetyl cysteine-induced blockade of cocaine-induced reinstatement. Ann NY Acad Sci. 2003; 1003:349-351. [PubMed: 14684458]

Bastian AJ. Learning to predict the future: the cerebellum adapts feedforward movement control. Curr Opin Neurobiol. 2006; 16:645-649. [PubMed: 17071073]

Bell RP, Garavan H, Foxe JJ. Neural correlates of craving and impulsivity in abstinent former cocaine users: towards biomarkers of relapse risk. Neuropharmacology. 2014; 85:461-470. [PubMed: 24951856]

Berglind WJ, Whitfield TW Jr, LaLumiere RT, Kalivas PW, McGinty JF. A single intra-PFC infusion of BDNF prevents cocaine-induced alterations in extracellular glutamate within the nucleus accumbens. J Neursci. 2009; 29:3715-3719.

Berk M, Malhi GS, Gray LJ, Dean OM. The promise of N-acetylcysteine in neuropsychiatry. Trends Pharmacol Sci. 2013; 34:167-177. [PubMed: 23369637]

Berridge KC, Robinson TE, Aldridge JW. Dissecting components of reward: 'liking', 'wanting', and learning. Curr Opin Pharmacol. 2009; 9:65-73. [PubMed: 19162544]

Biswal B, Yetkin FZ, Haughton VM, Hyde JS. Functional connectivity in the motor cortex of resting human brain using echo-planar MRI. Magn Reson Med. 1995; 34:537-541. [PubMed: 8524021]

Broadbent DE, Cooper PF, FitzGerald P, Parkes KR. The Cognitive Failures Questionnaire (CFQ) and its correlates. Br J Clin Psychol. 1982; 21(Pt 1):1-16. [PubMed: 7126941]

Brody AL, Mandelkern MA, London ED, Childress AR, Lee GS, Bota RG, Ho ML, Saxena S, Baxter LR Jr, Madsen D, Jarvik ME. Brain metabolic changes during cigarette craving. Arch Gen Psychiatry. 2002; 59:1162-1172. [PubMed: 12470133]

Cahill K, Stevens S, Perera R, Lancaster T. Pharmacological interventions for smoking cessation: an overview and network meta-analysis. Cochrane Database Syst Rev. 2013; 5:CD009329. [PubMed: 23728690]

CDC. annual smoking-attributable mortality, years of potential life lost, and productivity lossesUnited States, 1995-1999. MMWR. 2002; 51:300-313. [PubMed: 12002168]

Cook JW, Spring B, McChargue D, Hedeker D. Hedonic capacity, cigarette craving, and diminished positive mood. Nicotine Tob Res. 2004; 6:39-47. [PubMed: 14982686]

Doya K. Complementary roles of basal ganglia and cerebellum in learning and motor control. Curr Opin Neurobiol. 2000; 10:732-739. [PubMed: 11240282]

Dringen R, Gutterer JM, Gros C, Hirrlinger J. Aminopeptidase N mediates the utilization of the GSH precursor CysGly by cultured neurons. J Neurosci Res. 2001; 66:1003-1008. [PubMed: 11746430]

Duncan NW, Wiebking C, Tiret B, Marjanska M, Hayes DJ, Lyttleton O, Doyon J, Northoff G. Glutamate concentration in the medial prefrontal cortex predicts resting-state cortical-subcortical functional connectivity in humans. PLoS One. 2013; 8:e60312. [PubMed: 23573246]

Friston KJ, Jezzard P, Turner R. Analysis of functional MRI time-series. Hum Brain Mapp. 1994; $1: 153-171$.

Froeliger B, Crowell Beckham J, Feldman Dennis M, Victoria Kozink R, Joseph McClernon F. Effects of nicotine on emotional reactivity in PTSD and Non-PTSD smokers: results of a pilot fMRI Study. Adv Pharmacol Sci. 2012a; 2012:265724. [PubMed: 22719754]

Froeliger B, Modlin L, Wang L, Kozink RV, McClernon FJ. Nicotine withdrawal modulates frontal brain function during an affective Stroop task. Psychopharmacology (Berl). 2012b; 220:707-718. [PubMed: 21989805]

Froeliger B, Modlin LA, Kozink RV, Wang L, Garland EL, Addicott MA, McClernon FJ. Frontoparietal attentional network activation differs between smokers and nonsmokers during affective cognition. Psychiatry Res. 2013; 211:57-63. [PubMed: 23154092]

Drug Alcohol Depend. Author manuscript; available in PMC 2016 November 01. 
Froeliger B, Modlin LA, Kozink RV, Wang L, McClernon FJ. Smoking abstinence and depressive symptoms modulate the executive control system during emotional information processing. Addict Biol. 2012c; 17:668-679. [PubMed: 22081878]

Garland EL, Froeliger B, Howard MO. Mindfulness training targets neurocognitive mechanisms of addiction at the attention-appraisal-emotion interface. Front Psychiatry. 2014; 4:173. [PubMed: 24454293]

Gipson CD, Reissner KJ, Kupchik YM, Smith AC, Stankeviciute N, Hensley-Simon ME, Kalivas PW. Reinstatement of nicotine seeking is mediated by glutamatergic plasticity. Proc Natl Acad Sci USA. 2013; 110:9124-9129. [PubMed: 23671067]

Goldman M, Szucs-Reed RP, Jagannathan K, Ehrman RN, Wang Z, Li Y, Suh JJ, Kampman K, O'Brien CP, Childress AR, Franklin TR. Reward-related brain response and craving correlates of marijuana cue exposure: a preliminary study in treatment-seeking marijuana-dependent subjects. $\mathrm{J}$ Addict Med. 2013; 7:8-16. [PubMed: 23188041]

Goldstein RZ, Volkow ND. Drug addiction and its underlying neurobiological basis: neuroimaging evidence for the involvement of the frontal cortex. Am J Psychiatry. 2002; 159:1642-1652. [PubMed: 12359667]

Gonzales D, Rennard SI, Nides M, Oncken C, Azoulay S, Billing CB, Watsky EJ, Gong J, Williams KE, Reeves KR. Varenicline Phase 3 Study G. Varenicline, an alpha4beta2 nicotinic acetylcholine receptor partial agonist, vs sustained-release bupropion and placebo for smoking cessation: a randomized controlled trial. JAMA. 2006; 296:47-55. [PubMed: 16820546]

Gray KM, Watson NL, Carpenter MJ, Larowe SD. N-acetylcysteine (NAC) in young marijuana users: an open-label pilot study. Am J Addict. 2010; 19:187-189. [PubMed: 20163391]

Heatherton TF, Kozlowski LT, Frecker RC, Fagerstrom KO. The Fagerstrom Test for Nicotine Dependence: a revision of the Fagerstrom Tolerance Questionnaire. Br J Addict. 1991; 86:1119_ 1127. [PubMed: 1932883]

Hong LE, Gu H, Yang Y, Ross TJ, Salmeron BJ, Buchholz B, Thaker GK, Stein EA. Association of nicotine addiction and nicotine's actions with separate cingulate cortex functional circuits. Arch Gen Psychiatry. 2009; 66:431-441. [PubMed: 19349313]

Huang W, King JA, Ursprung W, Zheng S, Zhang N, Kennedy DN, Ziedonis D, DiFranza JR. The development and expression of physical nicotine dependence corresponds to structural and functional alterations in the anterior cingulate-precuneus pathway. Brain Behav. 2014; 4:408-417. [PubMed: 24944870]

Huang Z, Iv D, Yue Q, Wiebking C, Duncan NW, Zhang J, Wagner NF, Wolff A, Northoff G. Increase in glutamate/glutamine concentration in the medial prefrontal cortex during mental imagery: a combined functional mrs and fMRI study. Hum Brain Mapp. 2015 In press.

Janes AC, Pizzagalli DA, Richardt S, de BFB, Chuzi S, Pachas G, Culhane MA, Holmes AJ, Fava M, Evins AE, Kaufman MJ. Brain reactivity to smoking cues prior to smoking cessation predicts ability to maintain tobacco abstinence. Biol Psychiatry. 2010; 67:722-729. [PubMed: 20172508]

Jasinska AJ, Stein EA, Kaiser J, Naumer MJ, Yalachkov Y. Factors modulating neural reactivity to drug cues in addiction: a survey of human neuroimaging studies. Neurosci Biobehav Rev. 2014; 38:1-16. [PubMed: 24211373]

Jorenby DE, Hays JT, Rigotti NA, Azoulay S, Watsky EJ, Williams KE, Billing CB, Gong J, Reeves KR. Efficacy of varenicline, an alpha4beta2 nicotinic acetylcholine receptor partial agonist, vs placebo or sustained-release bupropion for smoking cessation: a randomized controlled trial. JAMA. 2006; 296:56-63. [PubMed: 16820547]

Kalivas PW. The glutamate homeostasis hypothesis of addiction. Nat Rev Neurosci. 2009; 10:561572. [PubMed: 19571793]

Kilts CD, Gross RE, Ely TD, Drexler KP. The neural correlates of cue-induced craving in cocainedependent women. Am J Psychiatry. 2004; 161:233-241. [PubMed: 14754771]

Knackstedt LA, LaRowe S, Mardikian P, Malcolm R, Upadhyaya H, Hedden S, Markou A, Kalivas $\mathrm{PW}$. The role of cystine-glutamate exchange in nicotine dependence in rats and humans. Biol Psychiatry. 2009; 65:841-845. [PubMed: 19103434]

Knutson B, Adams CM, Fong GW, Hommer D. Anticipation of increasing monetary reward selectively recruits nucleus accumbens. J Neurosci. 2001; 21:RC159. [PubMed: 11459880] 
Knutson B, Gibbs SE. Linking nucleus accumbens dopamine and blood oxygenation. Psychopharmacology (Berl). 2007; 191:813-822. [PubMed: 17279377]

Knutson B, Westdorp A, Kaiser E, Hommer D. FMRI Visualization of brain activity during a monetary incentive delay task. Neuroimage. 2000; 12:20-27. [PubMed: 10875899]

Kober H, Mende-Siedlecki P, Kross EF, Weber J, Mischel W, Hart CL, Ochsner KN. Prefrontalstriatal pathway underlies cognitive regulation of craving. Proc Natl Acad Sci. 2010; 107:1481114816. [PubMed: 20679212]

Koob GF, Le Moal M. Drug addiction, dysregulation of reward, and allostasis. Neuropsychopharmacology. 2001; 24:97-129. [PubMed: 11120394]

Koob GF, Le Moal M. Neurobiological mechanisms for opponent motivational processes in addiction. Philosoph Trans Royal Soc B Biol Sci. 2008; 363:3113-3123.

Kozink RV, Lutz AM, Rose JE, Froeliger B, McClernon FJ. Smoking withdrawal shifts the spatiotemporal dynamics of neurocognition. Addict Biol. 2010; 15:480-490. [PubMed: 21040240]

Kufahl PR, Li Z, Risinger RC, Rainey CJ, Wu G, Bloom AS, Li SJ. Neural responses to acute cocaine administration in the human brain detected by fMRI. Neuroimage. 2005; 28:904-914. [PubMed: 16061398]

Kupchik YM, Moussawi K, Tang XC, Wang X, Kalivas BC, Kolokithas R, Ogburn KB, Kalivas PW. The effect of $\mathrm{N}$-acetylcysteine in the nucleus accumbens on neurotransmission and relapse to cocaine. Biol Psychiatry. 2012; 71:978-986. [PubMed: 22137594]

LaRowe SD, Mardikian P, Malcolm R, Myrick H, Kalivas P, McFarland K, Saladin M, McRae A, Brady K. Safety and tolerability of $\mathrm{N}$-acetylcysteine in cocaine-dependent individuals. Am J Addict. 2006; 15:105-110. [PubMed: 16449100]

Lewerenz J, Hewett SJ, Huang Y, Lambros M, Gout PW, Kalivas PW, Massie A, Smolders I, Methner A, Pergande M, Smith SB, Ganapathy V, Maher P. The cystine/glutamate antiporter system x(c) $(-)$ in health and disease: from molecular mechanisms to novel therapeutic opportunities. Antiox Redox Signal. 2013; 18:522-555.

Li Q, Wang Y, Zhang Y, Li W, Yang W, Zhu J, Wu N, Chang H, Zheng Y, Qin W, Zhao L, Yuan K, Liu J, Wang W, Tian J. Craving correlates with mesolimbic responses to heroin-related cues in short-term abstinence from heroin: an event-related fMRI study. Brain Res. 2012; 1469:63-72. [PubMed: 22759909]

Ma N, Liu Y, Li N, Wang CX, Zhang H, Jiang XF, Xu HS, Fu XM, Hu X, Zhang DR. Addiction related alteration in resting-state brain connectivity. Neuroimage. 2010; 49:738-744. [PubMed: 19703568]

Manjón JV, Coupé P, Martí-Bonmatí L, Collins DL, Robles M. Adaptive non-local means denoising of MR images with spatially varying noise levels. J Magn Reson Imag. 2010; 31:192-203.

Mardikian PN, LaRowe SD, Hedden S, Kalivas PW, Malcolm RJ. An open-label trial of Nacetylcysteine for the treatment of cocaine dependence: a pilot study. Prog Neuropsychopharmacol Biol Psychiatry. 2007; 31:389-394. [PubMed: 17113207]

Matthews SC, Simmons AN, Lane SD, Paulus MP. Selective activation of the nucleus accumbens during risk-taking decision making. Neuroreport. 2004; 15:2123-2127. [PubMed: 15486494]

McClernon FJ, Hiott FB, Huettel SA, Rose JE. Abstinence-induced changes in self-report craving correlate with event-related fMRI responses to smoking cues. Neuropsychopharmacology. 2005; 30:1940-1947. [PubMed: 15920499]

McClernon FJ, Kozink RV, Lutz AM, Rose JE. 24-h smoking abstinence potentiates fMRI-BOLD activation to smoking cues in cerebral cortex and dorsal striatum. Psychopharmacology (Berl). 2009; 204:25-35. [PubMed: 19107465]

McClure EA, Baker NL, Gipson CD, Carpenter MJ, Roper AP, Froeliger BE, Kalivas PW, Gray KM. An open-label pilot trial of N-acetylcysteine and varenicline in adult cigarette smokers. Am J Drug Alcohol Abuse. 2014a; 41:52-56. [PubMed: 25062287]

McClure EA, Gipson CD, Malcolm RJ, Kalivas PW, Gray KM. potential role of n-acetylcysteine in the management of substance use disorders. CNS Drugs. 2014b; 28:95-106. [PubMed: 24442756]

Moreno-López L, Perales JC, Son D, Albein-Urios N, Soriano-Mas C, Martinez-Gonzalez JM, Wiers RW, Verdejo-García A. Cocaine use severity and cerebellar gray matter are associated with 
reversal learning deficits in cocaine-dependent individuals. Addict Biol. 2015; 20:546-556. [PubMed: 24738841]

Motzkin JC, Baskin-Sommers A, Newman JP, Kiehl KA, Koenigs M. Neural correlates of substance abuse: reduced functional connectivity between areas underlying reward and cognitive control. Hum Brain Mapp. 2014; 35:4282-4292. [PubMed: 24510765]

Moussawi K, Pacchioni A, Moran M, Olive MF, Gass JT, Lavin A, Kalivas PW. N-Acetylcysteine reverses cocaine-induced metaplasticity. Nat Neurosci. 2009; 12:182-189. [PubMed: 19136971]

Oncken C, Gonzales D, Nides M, Rennard S, Watsky E, Billing CB, Anziano R, Reeves K. Efficacy and safety of the novel selective nicotinic acetylcholine receptor partial agonist, varenicline, for smoking cessation. Arch Intern Med. 2006; 166:1571-1577. [PubMed: 16908789]

Pierce RC, Bell K, Duffy P, Kalivas PW. Repeated cocaine augments excitatory amino acid transmission in the nucleus accumbens only in rats having developed behavioral sensitization. $\mathrm{J}$ Neurosci. 1996; 16:1550-1560. [PubMed: 8778304]

Prado E, Maes M, Piccoli LG, Baracat M, Barbosa DS, Franco O, Dodd S, Berk M, Vargas Nunes SO. $\mathrm{N}$-acetylcysteine for therapy-resistant tobacco use disorder: a pilot study. Redox Rep. 2015; 20:215-222. [PubMed: 25729878]

Radloff LS. The CES-D scale: A self report depression scale for research in the general population. Appl Psychol Measure. 1977; 1:385-401.

Rajapakse JC, Giedd JN, Rapoport JL. Statistical approach to segmentation of single-channel cerebral MR images. IEEE Trans Med Imaging. 1997; 16:176-186. [PubMed: 9101327]

Reichel CM, Moussawi K, Do PH, Kalivas PW, See RE. Chronic N-acetylcysteine during abstinence or extinction after cocaine self-administration produces enduring reductions in drug seeking. $\mathrm{J}$ Pharmacol Exp Ther. 2011; 337:487-493. [PubMed: 21303920]

Reissner KJ, Kalivas PW. Using glutamate homeostasis as a target for treating addictive disorders. Behav Pharmacol. 2010; 21:514-522. [PubMed: 20634691]

Risinger RC, Salmeron BJ, Ross TJ, Amen SL, Sanfilipo M, Hoffmann RG, Bloom AS, Garavan H, Stein EA. Neural correlates of high and craving during cocaine self-administration using BOLD fMRI. Neuroimage. 2005; 26:1097-1108. [PubMed: 15886020]

Rogers RD, Ramnani N, Mackay C, Wilson JL, Jezzard P, Carter CS, Smith SM. Distinct portions of anterior cingulate cortex and medial prefrontal cortex are activated by reward processing in separable phases of decision-making cognition. Biol Psychiatry. 2004; 55:594-602. [PubMed: 15013828]

Rushworth MF, Buckley MJ, Behrens TE, Walton ME, Bannerman DM. Functional organization of the medial frontal cortex. Curr Opin Neurobiol. 2007; 17:220-227. [PubMed: 17350820]

Schmaal L, Berk L, Hulstijn KP, Cousijn J, Wiers RW, van den Brink W. Efficacy of N-acetylcysteine in the treatment of nicotine dependence: a double-blind placebo-controlled pilot study. Eur Addict Res. 2011; 17:211-216. [PubMed: 21606648]

Schmaal L, Veltman DJ, Nederveen A, van den Brink W, Goudriaan AE. N-acetylcysteine normalizes glutamate levels in cocaine-dependent patients: a randomized crossover magnetic resonance spectroscopy study. Neuropsychopharmacology. 2012; 37:2143-2152. [PubMed: 22549117]

Shiffman S, Paty JA, Gnys M, Kassel JA, Hickcox M. First lapses to smoking: within-subjects analysis of real-time reports. J Consult Clin Psychol. 1996; 64:366-379. [PubMed: 8871421]

Shiffman SM, Jarvik ME. Smoking withdrawal symptoms in two weeks of abstinence. Psychopharmacology. 1976; 50:35-39. [PubMed: 827760]

Shmuel A, Leopold DA. Neuronal correlates of spontaneous fluctuations in fMRI signals in monkey visual cortex: implications for functional connectivity at rest. Hum Brain Mapp. 2008; 29:751761. [PubMed: 18465799]

Stolerman IP, Jarvis MJ. The scientific case that nicotine is addictive. Psychopharmacology (Berl). 1995; 117:2-10. discussion 14-20. [PubMed: 7724697]

Taylor RC, Harris NA, Singleton EG, Moolchan ET, Heishman SJ. Tobacco craving: intensity-related effects of imagery scripts in drug abusers. Exp Clin Psychopharmacol. 2000; 8:75. [PubMed: 10743907]

Tohka J, Zijdenbos A, Evans A. Fast and robust parameter estimation for statistical partial volume models in brain MRI. Neuroimage. 2004; 23:84-97. [PubMed: 15325355] 
Tzvi E, Münte TF, Krämer UM. Delineating the cortico-striatal-cerebellar network in implicit motor sequence learning. Neuroimage. 2014; 94:222-230. [PubMed: 24632466]

Volkow ND, Wang GJ, Fowler JS, Logan J, Gatley SJ, Hitzemann R, Chen AD, Dewey SL, Pappas N. Decreased striatal dopaminergic responsiveness in detoxified cocaine-dependent subjects. Nature. 1997; 386:830-833. [PubMed: 9126741]

Wang Z, Faith M, Patterson F, Tang K, Kerrin K, Wileyto EP, Detre JA, Lerman C. Neural substrates of abstinence-induced cigarette cravings in chronic smokers. J Neurosci. 2007; 27:14035-14040. [PubMed: 18094242]

Watson D, Clark LA, Tellegen A. Development and validation of brief measures of positive and negative affect: the PANAS scales. J Pers Soc Psychol. 1988; 54:1063-1070. [PubMed: 3397865]

Westman EC, Behm FM, Simel DL, Rose JE. smoking behavior on the first day of a quit attempt predicts long-term abstinence. Arch Intern Med. 1997; 157:335-340. [PubMed: 9040302]

Wilson SJ, Sayette MA. Neuroimaging craving: urge intensity matters. Addiction. 2014; 110:195-203. [PubMed: 25073979]

Zink CF, Pagnoni G, Martin ME, Dhamala M, Berns GS. Human striatal response to salient nonrewarding stimuli. J Neurosci. 2003; 23:8092-8097. [PubMed: 12954871] 


\section{Highlight}

We examine the effects of $\mathrm{N}$-Acetylcysteine on maintaining smoking abstinence.

fMRI resting-state connectivity in corticostriatal circuitry was assessed

Relations between neural circuitry function and smoking withdrawal and abstinence was assessed. 
A)

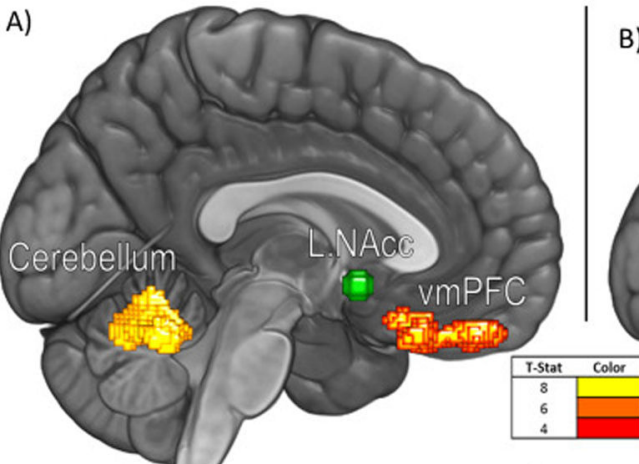

$\square$-Acetylcysteine

Dlacebo

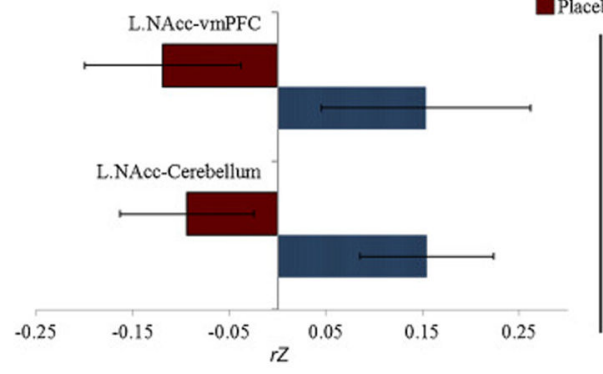

B)
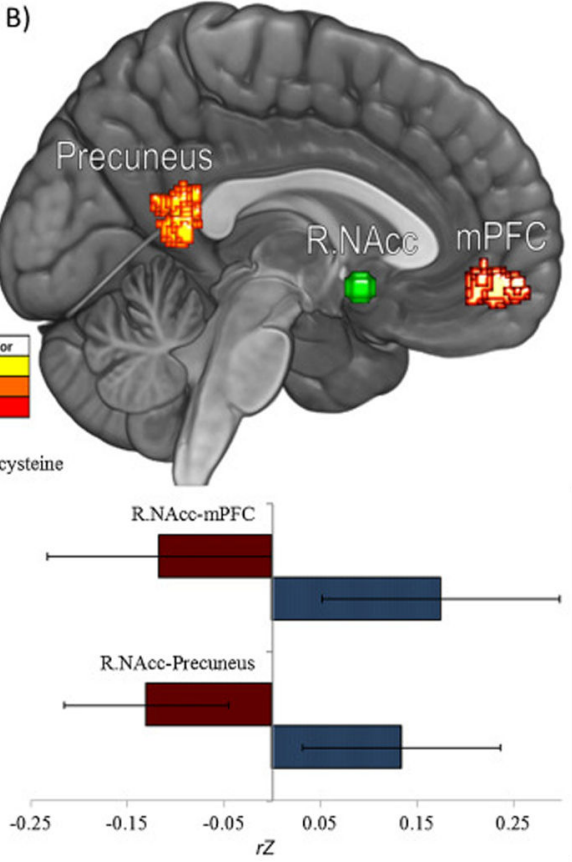

Figure 1.

Resting-state functional connectivity (rsFC) in: A) corticostriatal circuitry: between right Nucleus Accumbens (NAcc) ROI seed and medial prefrontal cortex (mPFC) and Precuneus; and B) left NAcc seed and ventromedial PFC and Cerebellum. As compared to the placebo group, smokers that received $\mathrm{N}$-Acetylcysteine exhibited stronger $\mathrm{rsFC}$ in pathways $\mathrm{A}$ and $\mathrm{B}$ $(\mathrm{F}<.025, \mathrm{FWE})$. 
A. rsFC correlates of recency of smoking (CO-ppm)

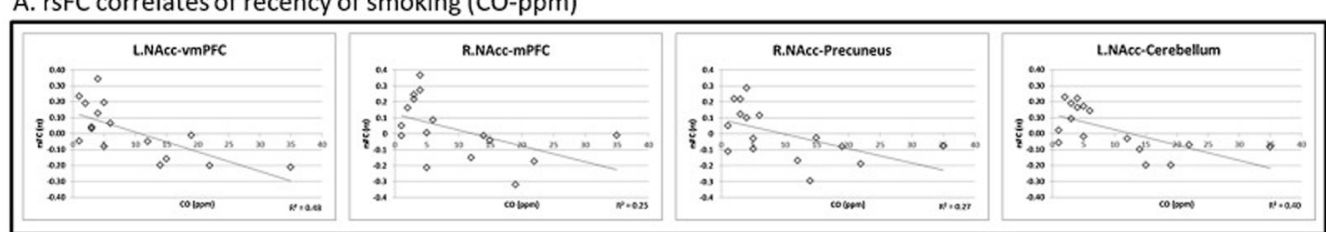

B. rsFC correlates of Craving

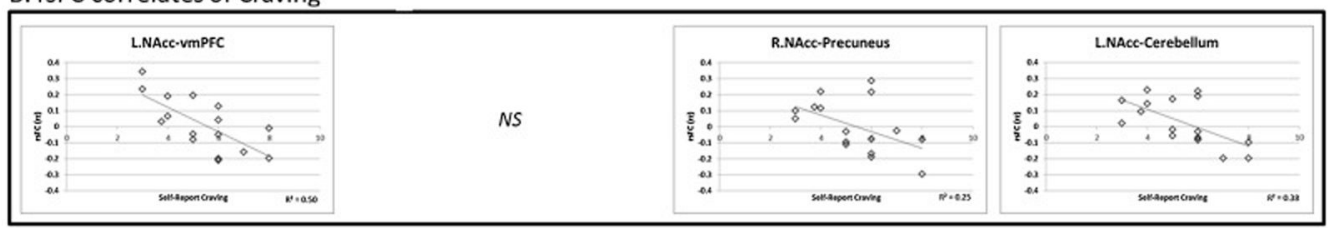

C. rsFC correlates of Positive Affect

\begin{tabular}{|c|c|c|c|c|c|}
\hline & L.NACE-VmPFC & R.NAcC-mPFC & & & L.NACC-Cerebellum \\
\hline 法 & $\infty 0^{\circ}$ & $\because 8$ & & 告 & \\
\hline 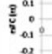 & 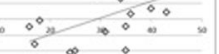 & 蛋: & NS & 疍, & $=0, \infty 8^{\circ}=$ \\
\hline 赵 & 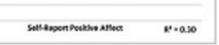 & 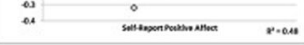 & & 党 & 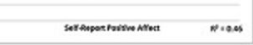 \\
\hline
\end{tabular}

Figure 2. 


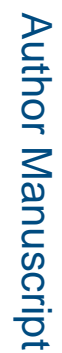

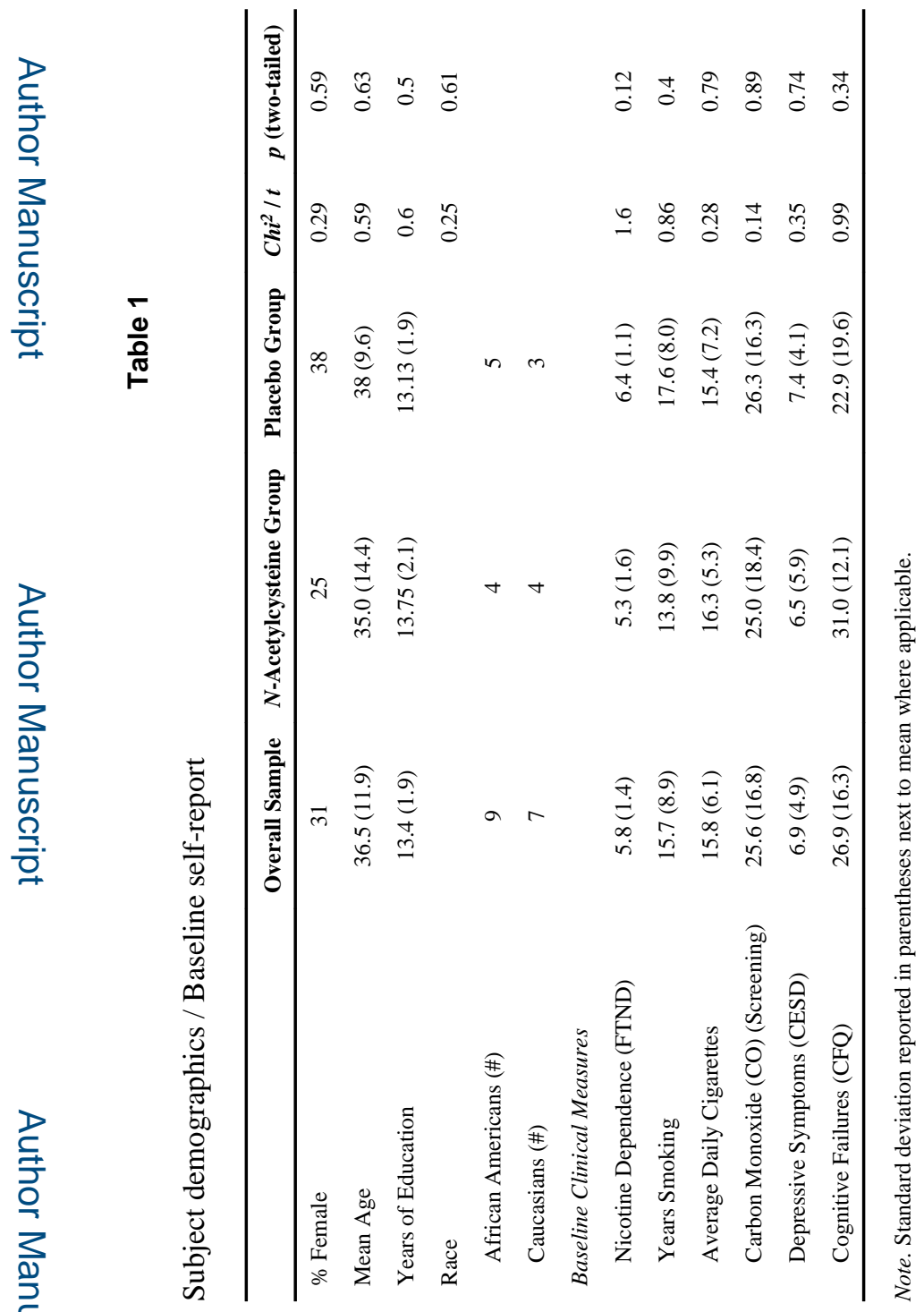

Drug Alcohol Depend. Author manuscript; available in PMC 2016 November 01. 


\section{Table 2}

\section{Adverse Events}

\begin{tabular}{lcc}
\hline Group (Total) & $\boldsymbol{N}$-Acetylcysteine (5) & Placebo (12) \\
\hline Event type & 2 & - \\
Reflux & - & 4 \\
Bad Aftertaste & - & 3 \\
Fatigue & - & 1 \\
Dry Mouth & 2 & - \\
Light-Headed & 1 & 2 \\
Nausea & - & 1 \\
Vomiting & - & 1 \\
Irritability & &
\end{tabular}

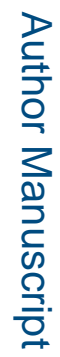

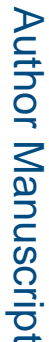


Table 3

\begin{tabular}{|c|c|c|c|c|c|}
\hline \multicolumn{5}{|c|}{ GROUP } & \multirow{2}{*}{$\begin{array}{c}\text { Overall Model } \\
F(p) \\
\end{array}$} \\
\hline & $N$-Acetylcysteine & Placebo & $t$ & $p$ & \\
\hline Screening & $25.0(18.4)$ & $26.3(16.2)$ & 0.1 & $\mathrm{~ns}^{d}$ & $3.74(.043)^{*}$ \\
\hline Abst. Day 1 & $10.0(6.0)$ & $11.75(8.4)$ & 0.5 & $\mathrm{~ns}^{d}$ & \\
\hline Abst. Day 2 & $4.4(3.4)$ & $13.3(6.5)$ & 3.4 & $0.004^{* *}$ & \\
\hline Abst. Day $3^{c}$ & - & - & - & - & \\
\hline Abst. Day 4 (fMRI visit) & $3.5(1.6)$ & $15.4(10.5)$ & 3.12 & $0.007^{* *}$ & \\
\hline
\end{tabular}

\begin{tabular}{|c|c|c|c|c|c|}
\hline \multicolumn{5}{|c|}{ GROUP } & \multirow{2}{*}{$\frac{\text { Overall Model }}{F(p)}$} \\
\hline & $N$-Acetylcysteine & Placebo & $t$ & $p$ & \\
\hline Screening & $32.8(6.3)$ & $34.7(7.7)$ & 0.5 & $\mathrm{~ns}^{d}$ & $3.66(0.036)^{*}$ \\
\hline Abst. Day 1 & $33.5(6.5)$ & $29.8(9.2)$ & 0.9 & $\mathrm{~ns}^{d}$ & \\
\hline Abst. Day 2 & $33.9(6.6)$ & $28.6(7.1)$ & 1.5 & $\mathrm{~ns}^{d}$ & \\
\hline Abst. Day 3 & $33.3(5.4)$ & $26.9(6.6)$ & 2.1 & $0.050^{*}$ & \\
\hline Abst. Day 4 (fMRI visit) & $37.0(4.9)$ & $25.1(7.8)$ & 3.6 & $0.003^{* *}$ & \\
\hline
\end{tabular}

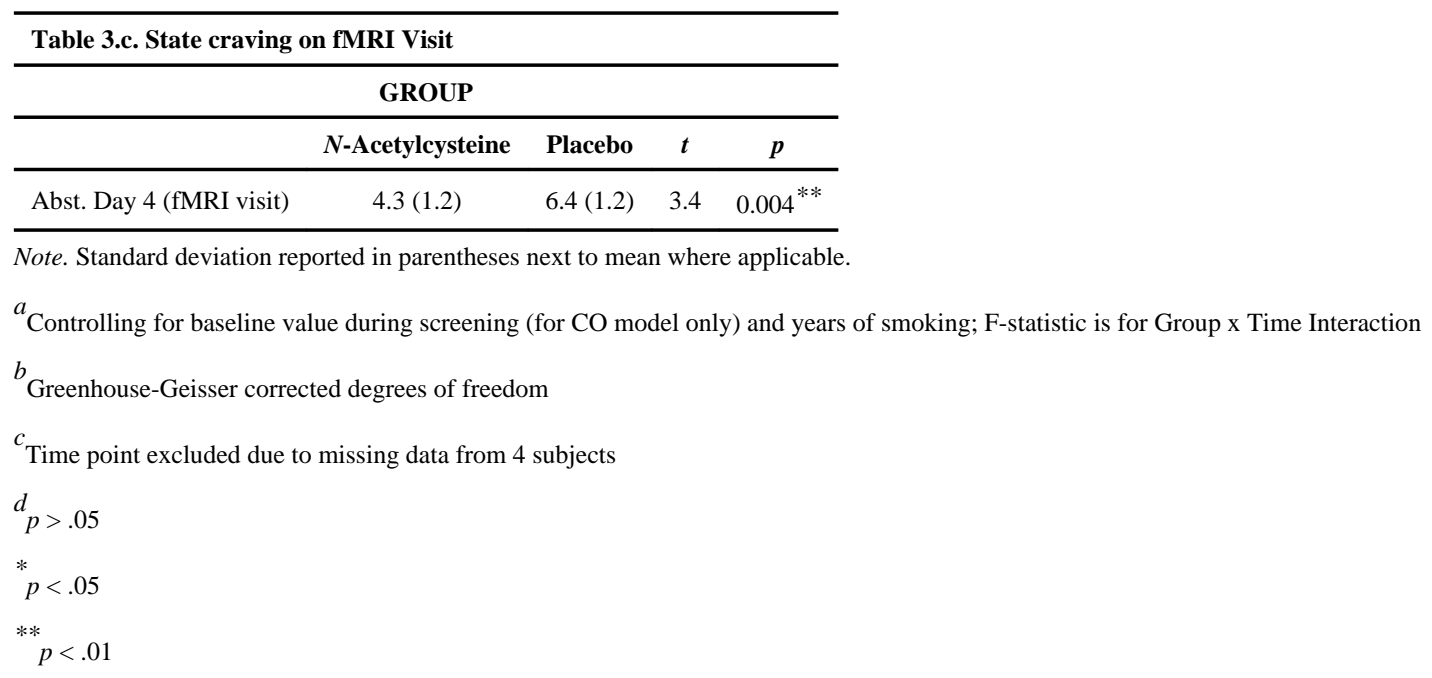

Note. Standard deviation reported in parentheses next to mean where applicable. 


\section{Table 4}

Main effect of condition on resting-state functional connectivity with the nucleus accumbens

\begin{tabular}{|c|c|c|c|c|}
\hline \multirow{3}{*}{$\begin{array}{l}\text { Pattern of Group Contrast: } \\
\text { Seed: } \\
\text { Correlated Brain Region(s) }\end{array}$} & \multicolumn{4}{|c|}{$N$-Acetylcysteine $>$ Placebo } \\
\hline & \multicolumn{2}{|c|}{ Left Nucleus Accumbens } & \multicolumn{2}{|c|}{ Right Nucleus Accumbens } \\
\hline & Cerebellum & $\mathrm{vmPFC}^{c}$ & Precuneus & $\mathrm{mPFC}^{c}$ \\
\hline Peak MNI Coordinates $[\mathrm{x}, \mathrm{y}, \mathrm{z}]$ & $-10,-60,-22$ & $10,24,-26$ & $8,-51,8$ & $-9,50,-9$ \\
\hline Cluster Size $\left(\mathrm{mm}^{3}\right)$ & 3375 & 1954 & 1563 & 1384 \\
\hline$N$-acetylcysteine ${ }^{a}$ & $0.15(.07)$ & $0.15(.11)$ & $0.13(.10)$ & $0.17(.12)$ \\
\hline $\operatorname{Placebo}^{a}$ & $-0.09(.07)$ & $-0.12(.08)$ & $-0.13(.09)$ & $-0.11(.12)$ \\
\hline$t$ - statistic & 8.72 & 6.73 & 6.53 & 4.83 \\
\hline$p_{\text {cluster }}$ FWE & 0.000 & 0.005 & 0.010 & 0.017 \\
\hline cohen's $D^{b}$ & 0.95 & 0.88 & 0.87 & 0.84 \\
\hline
\end{tabular}

Note. Standard deviation reported in parentheses next to mean where applicable.

All correlations significant at $\mathrm{p}<.001$ cluster-forming and $\mathrm{p}<.05$ FWE cluster-level

$a_{\text {group mean cluster } r Z \text { value }}$

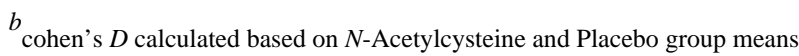

${ }^{c}$ denotes ventromedial and medial prefrontal cortices respectively 